\title{
Analysis of hospital discharge data to characterize obstructive sleep apnea and its management in adult patients hospitalized in Canada: 2006 to 2007
}

\author{
Kathy F Spurr BSc RRT MHI ${ }^{1}$, Debra L Morrison MD FRCPC ${ }^{2}$, Michael A Graven MD MPH FAAP ${ }^{3,4}$, \\ Adam Webber $\mathrm{MSc}^{5}$, Robert W Gilbert $\mathrm{PhD}^{1}$
}

\begin{abstract}
KF Spurr, DL Morrison, MA Graven, A Webber, RW Gilbert. Analysis of hospital discharge data to characterize obstructive sleep apnea and its management in adult patients hospitalized in Canada: 2006 to 2007. Can Respir J 2010;17(5):213-218.
\end{abstract}

BACKGROUND: Diagnosed obstructive sleep apnea (OSA) affects 2\% to $7 \%$ of middle-age persons worldwide and represents a substantial health care burden. The gold standard for treating OSA in adults is continuous positive airway pressure (CPAP) therapy. Compliance with this treatment is especially important in OSA patients experiencing concomitant acute and chronic disease or illness, and those undergoing procedures associated with sedation, analgesia and anesthesia.

OBJECTIVE: To describe the clinical characteristics and management of hospitalized OSA patients in Canada.

METHODS: Using the Canadian Institute for Health Information's hospital Discharge Abstract Database (fiscal year 2006/2007), a retrospective cohort study of all acute care patients discharged with a diagnosis that included OSA was performed.

RESULTS: An examination of the discharge data of 2,400,245 acute care hospital abstracts identified 8823 cases of OSA. The mean age of OSA patients was 45.7 years and $66.5 \%$ were men. The most common comorbidities in the adult OSA population were obesity, cardiovascular disease, type 2 diabetes mellitus and chronic obstructive pulmonary disease. In adult OSA patients, the reported surgical intervention rate using uvulopalatopharyngoplasty $(9.6 \%)$ was much higher than interventional CPAP therapy $(4.8 \%)$.

CONCLUSIONS: Only a small percentage of hospitalized OSA patients were documented as having received CPAP therapy during their stay. Issues relating to the accuracy, specificity and completeness of the Canadian Institute for Health Information's hospital Discharge Abstract Database specific to OSA and its management were identified. Practices pertaining to the reporting, coding and management of hospitalized adult OSA patients warrant further investigation and research.

Key Words: Canadian Institute for Health Information; Continuous positive airway pressure; Discharge abstract database; Obstructive; Patient discharge; Sleep apnea; Sleep apnea syndromes

\author{
L'analyse des données de congé hospitalier pour \\ caractériser l'apnée obstructive du sommeil et sa \\ prise en charge chez les patients hospitalisés au \\ Canada : 2006 à 2007
}

\begin{abstract}
HISTORIQUE : L'apnée obstructive du sommeil (AOS) diagnostiquée touche de $2 \%$ à $7 \%$ des personnes d'âge mûr dans le monde et représente un important fardeau pour les soins de santé. La norme de référence pour traiter l'AOS chez les adultes est une thérapie par pression positive continue (PPC). Il est particulièrement important que les patients ayant une AOS respectent ce traitement s'ils sont atteints d'une maladie aiguë ou chronique concomitante ou doivent subir une intervention exigeant une sédation, une analgésie ou une anesthésie.
\end{abstract}

OBJECTIF : Décrire les caractéristiques cliniques et la prise en charge des patients hospitalisés ayant une AOS au Canada.

MÉTHODOLOGIE : Au moyen de la base de données sur les congés des patients (exercice financier 2007) de l'Institut canadien d'information sur la santé, les chercheurs ont formé une étude de cohorte rétrospective de tous les patients en soins aigus ayant obtenu leur congé avec un diagnostic incluant l'AOS.

RÉSULTATS : L'examen des données sur les congés de 2400245 résumés de dossiers hospitaliers en soins aigus a permis de repérer 8823 cas d'AOS. Les patients ayant une AOS avaient un âge moyen de 45,7 ans, et $66,5 \%$ étaient des hommes. Les principales comorbidités au sein de la population adulte ayant une AOS étaient l'obésité, les maladies cardiovasculaires, le diabète de type 2 et la maladie obstructive pulmonaire chronique. Chez les patients adultes ayant une AOS, le taux d'intervention chirurgicale déclarée faisant appel à l'uvulopalatopharyngoplastie (9,6 \%) était beaucoup plus élevé que la thérapie interventionnelle par PPC (4,8\%).

CONCLUSIONS : Seul un faible pourcentage de patients hospitalisés ayant une AOS était documenté comme ayant reçu une thérapie par PPC pendant leur séjour. Les chercheurs ont repéré des questions liées à l'exactitude, à la spécificité et à l'exhaustivité de la base de données sur les congés des patients de l'Institut canadien d'information sur la santé propres à l'AOS et à sa prise en charge. Les pratiques liées à la déclaration, au codage et à la prise en charge des patients adultes hospitalisés ayant une AOS méritent une exploration et des recherches plus approfondies.

important in OSA patients experiencing concomitant acute and chronic disease and illness (11). Furthermore, patients with OSA undergoing procedures associated with sedation, analgesia and anesthesia are considered to be at an increased risk of adverse events $(10,12)$. The Canadian Thoracic Society Sleep Disordered Breathing Committee (6) and the American Society of Anesthesiologists (13) recommend the use of CPAP therapy perioperatively. While a number of studies $(14,15)$ have determined the long-term compliance rate for homedelivered CPAP therapy to be between $46 \%$ and $85 \%$, little is known about the clinical management of OSA in patients admitted to hospital in Canada. adult men and $2 \%$ to $5 \%$ for adult women $(1-3)$. It is estimated that $70 \%$ to $80 \%$ of persons affected with sleep apnea remain undiagnosed $(4,5)$.

The gold standard therapy for the management of OSA in adults - continuous positive airway pressure (CPAP) - produces significant improvement in measures of objective and subjective daytime sleepiness, quality of life, cognitive function, systolic and diastolic blood pressure, minimum oxygen saturation and sleep efficiency in patients with moderate to severe OSA (6-10). Compliance with CPAP therapy may be especially

${ }^{1}$ School of Health Sciences; ${ }^{2}$ Department of Medicine; ${ }^{3}$ Department of Pediatrics, Dalhousie University; ${ }^{4}$ IWK Health Centre; ${ }^{5}$ Addiction

Prevention and Treatment Services, Capital District Health Authority, Halifax, Nova Scotia

Correspondence: Ms Kathy F Spurr, School of Health Sciences, Dalhousie University, 1276 South Park Street, Halifax, Nova Scotia B3H 2 Y9.

Telephone 902-473-2382,fax 902-473-5115, e-mail kfspurr@dal.ca 


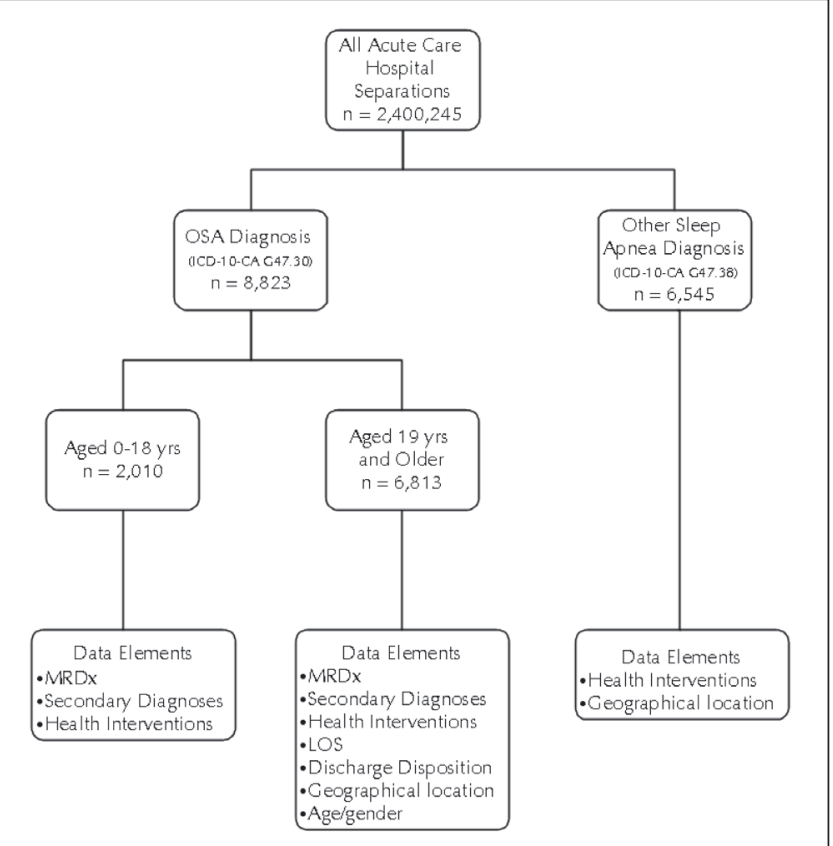

Figure 1) Canadian Institute for Health Information Discharge Abstract Database (2006/2007) data extraction flowchart. ICD10-CA International Classification of Diseases, 10th Revision Canadian Enhancement; LOS Length of stay; MRDx Most responsible diagnosis; OSA Obstructive sleep apnea; yrs Years

To obtain prospective national estimates of the prevalence of OSA in hospitalized patients and its management would be expensive, while data obtained from a limited population or collected over a short time period would have poor external validity. National hospital discharge databases, such as the Canadian Institute for Health Information Discharge Abstract Database (CIHI-DAD), are a necessary tool for determining such estimates. Such information is important for informing health care practice and directing the allocation of health care and research resources for OSA in Canada.

In the present study, we used the CIHI-DAD to retrospectively examine the following: the prevalence and demographic and clinical characteristics of Canadian hospitalized adult patients diagnosed with OSA; how OSA is clinically managed in these patients in Canada; and the capacity of the CIHIDAD to further our understanding of the way in which OSA is reported and managed in hospitalized patients.

\section{METHODS}

\section{Data source}

Data for the current retrospective study were extracted from the CIHI-DAD. The CIHI is a federally chartered institution established in 1994 to provide health information pertinent to health services and research initiatives in Canada. The CIHI-DAD includes abstracted information on all patient separations (discharge, death, sign out or transfer of the patient to another facility [excluding still births and cadaveric donors]) from all acute inpatient institutions in the Canadian provinces and territories, except Quebec, which does not participate. Abstracts are completed by hospital-based coders after patient separation.

Data contained within the 2006/2007 fiscal year CIHIDAD included demographic (sex, age, province of residence and home postal code), administrative (date of admission and date of discharge) and clinical elements (status at discharge, the most responsible diagnosis [MRDx] and as many as 15 secondary diagnoses [coded according to the International Classification of Diseases, 10th Revision, Canadian Enhancement [ICD-10-CA] and up to 10 diagnostic, therapeutic and support interventions coded according to the Canadian Classification of Health Interventions [CCI]).

\section{Data extraction}

For the present study, the CIHI-DAD was reviewed to identify all patients with a diagnosis that included sleep apnea (ICD-10-CA code G47.30 for 'sleep apnea, obstructive' and G47.38 for 'other sleep apnea') during the 2006/2007 fiscal year (April 1, 2006 through March 31, 2007) (Figure 1). The diagnostic category 'other sleep apneas' includes sleep apneas of the mixed type, congenital hypoventilation syndrome, Ondine's curse and unspecified sleep apneas (eg, cases in which 'sleep apneas' was recorded on the patient record but not specified according to type). Central sleep apnea has a unique specific code and was not examined.

Information regarding patients' age, sex, province of residence, length of hospital stay, status at discharge, MRDx, secondary diagnosis and health interventions was collected. Data records for patients coded for 'other sleep apneas' were extracted, and information on the patient's province of residence and health interventions were sought. Ethics approval for the present study was obtained from the Dalhousie University Health Sciences Research Ethics Board (Halifax, Nova Scotia).

\section{Statistical analysis}

All data were analyzed with SAS version 9.1 (SAS Institute, USA), under license to Dalhousie University. Descriptive statistical analyses were conducted to evaluate demographic variables, clinical characteristics and the clinical management of sleep apnea; $\chi^{2}$ tests were used to compare CPAP and nonCPAP users.

\section{RESULTS}

Prevalence of sleep apnea in acute care hospitalizations in Canada: Fiscal year 2006/2007

From a total of 2,400,245 acute care hospital separations, the records of 8823 OSA and 6545 'other sleep apnea' patients were identified, collectively representing $0.64 \%$ of all hospital separations during the period of investigation. Figure 2 shows the prevalence of OSA and 'other sleep apneas' per 1000 separations according to provincial/territorial location. The highest reporting for OSA was in the province of Alberta and the lowest was for Prince Edward Island. With regard to 'other sleep apneas', Alberta reported the highest prevalence while British Columbia reported the lowest.

\section{Demographics and clinical elements of acute care patients with OSA}

The mean age of OSA patients was 45.7 years and $66.5 \%$ were men. Figure 3 illustrates the age distribution according to decade. In this population of OSA patients, 2010 were 18 years of age and younger (children and adolescents), while 6813 were 19 years of age and older (adults). Table 1 summarizes the MRDx for the adult population. The MRDx was defined as the diagnosis most 


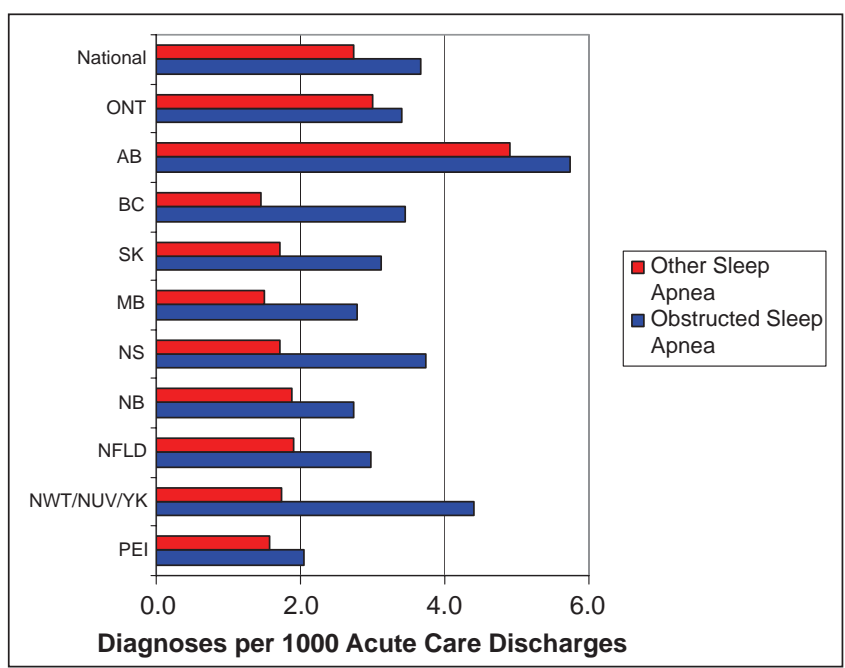

Figure 2) Distribution according to province/territory of all sleep apnea diagnoses (obstructive sleep apnea and 'other sleep apnea') per 1000 acute care discharges: Canadian Institute for Health Information Discharge Abstract Database, fiscal year 2006/2007. AB Alberta; BC British Columbia; MB Manitoba; NB New Brunswick; NFLD Newfoundland and Labrador; NS Nova Scotia; NUV Nunavut; NWT Northwest Territories; ONT Ontario; PEI Prince Edward Island; SK Saskatchewan; YK Yukon

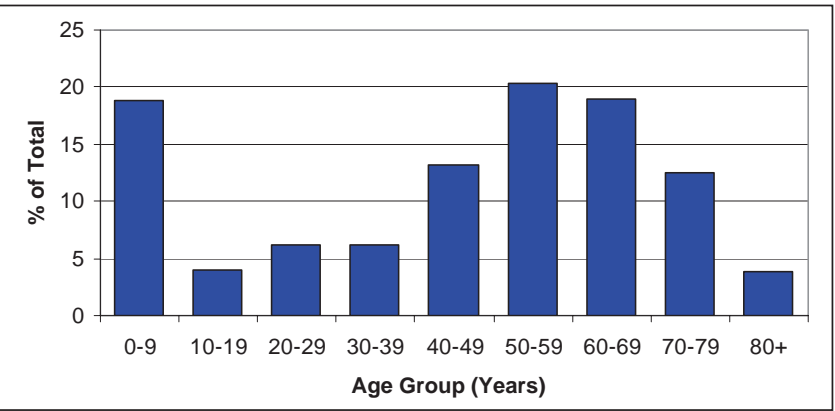

Figure 3) Age distribution of obstructive sleep apnea diagnoses in separations from acute care hospitals in Canada: Canadian Institute for Health Information Discharge Abstract Database, fiscal year 2006/2007

responsible for the patients' stay in the hospital, which does not necessarily correspond to the reason for admission (16). Other than OSA, the most common MRDx for adults with OSA was congestive heart failure (ICD-10-CA code I50.0), followed by deviated nasal septum (ICD-10-CA code J34.3), acute exacerbation of chronic obstructive pulmonary disease (COPD) (ICD-10-CA code J44.1), atherosclerotic heart disease (ICD10-CA code I25.10) and COPD with lower respiratory infection (ICD-10-CA code J44.0). This particular adult cohort of 1116 patients $(16.4 \%)$ had OSA as their MRDx.

Table 2 presents data regarding the most common secondary diagnosis for the adult OSA population. The most common secondary diagnosis was benign hypertension (ICD-10-CA code I10.0) followed by type 2 diabetes with cardiovascular complications (ICD-10-CA code E11.52), morbid obesity (ICD-10-CA code E66.8), congestive heart failure (ICD10-CA code $\mathrm{I} 50.0$ ) and abnormal blood glucose levels (ICD10-CA code R73.812).
TABLE 1

Most common, most responsible diagnoses in adult patients coded with a discharge diagnosis that included obstructive sleep apnea: CIHI-DAD, fiscal year 2006/2007

\begin{tabular}{lr}
\hline Diagnosis & $\%$ \\
\hline Obstructive sleep apnea & 16.38 \\
Congestive heart failure & 6.00 \\
Deviated nasal septum & 3.42 \\
Acute exacerbation of COPD & 3.33 \\
Atherosclerotic heart disease & 2.74 \\
COPD with lower respiratory tract infection & 2.45 \\
\hline
\end{tabular}

CIHI-DAD Canadian Institute for Health Information Discharge Abstract Database; COPD Chronic obstructive pulmonary disease

\section{TABLE 2}

Most common secondary diagnoses in adult patients coded with a discharge diagnosis that included obstructive sleep apnea: CIHI-DAD, fiscal year 2006/2007

\begin{tabular}{lc}
\hline Diagnosis & $\%$ \\
\hline Benign hypertension & 27.81 \\
Type 2 diabetes with cardiovascular complications & 13.36 \\
Morbid obesity & 12.26 \\
Congestive heart failure & 11.35 \\
Abnormal blood glucose levels & 10.98 \\
\hline
\end{tabular}

CIHI-DAD Canadian Institute for Health Information Discharge Abstract Database

Health interventions and patients coded for OSA

The most common health interventions (diagnostic, supportive or therapeutic) administered to adults with a discharge diagnosis that included OSA were uvulopalatopharyngoplasty (UPPP) (9.6\%, CCI code 1.FQ.78LA), followed by invasive (via endotracheal or tracheostomy tube) CPAP/bilevel positive airway pressure (BiPAP) therapy (9.1\%, CCI code 1.GZ.31. CA-ND) and noninvasive CPAP/BiPAP therapy $(4.8 \%$, CCI code 1.GZ.31.CB-ND).

Use of noninvasive ventilation CPAP/BiPAP therapy in adult OSA patients in Canada

CPAP is the gold standard therapy for managing OSA in adults. As described above, $4.8 \%$ of adult OSA patients were abstracted as receiving CPAP/BiPAP therapy while in hospital. Currently, codes used in the CCI classification system do not permit the separation of noninvasive positive pressure therapies and, therefore, it was not possible to determine whether these patients received CPAP or BiPAP.

Positive pressure (CPAP/BiPAP) therapy and length of hospital stay

Table 3 presents data regarding the mean, median, and first and third quartiles for length of hospital stay comparing adult OSA patients receiving CPAP/BiPAP therapy versus those who did not. The median length of stay was increased by four days for patients who used CPAP/BiPAP therapy.

Disposition at discharge

The data presented in Table 4 compares the discharge disposition for adult OSA patients who received CPAP/BiPAP therapy with those who did not. The majority of patients from both groups were discharged home; however, those receiving noninvasive CPAP/BiPAP therapy had a significantly different 


\section{TABLE 3 \\ Length of hospital stay (days) for adult patients coded with a discharge diagnosis that included obstructive sleep apnea and according to the receipt of CPAP/BiPAP therapy: CIHI-DAD, fiscal year 2006/2007}

\begin{tabular}{lcc}
\hline & \multicolumn{2}{c}{ CPAP/BiPAP } \\
\cline { 2 - 3 } & Therapy & No therapy \\
\hline Mean \pm SD & $15.48 \pm 28.7$ & $9.83 \pm 18.7$ \\
Median & 8 & 4 \\
First quartile & 2 & 4 \\
Third quartile & 16 & 10 \\
\hline
\end{tabular}

BiPAP Bilevel positive airway pressure; CIHI-DAD Canadian Institute for Health Information Discharge Abstract Database; CPAP Continuous positive airway pressure

discharge disposition distribution $(\mathrm{P}<0.0001)$ - notably, they were much less likely to be discharged home and more likely to be discharged to continuing care or home with support services.

\section{Health interventions for adult patients coded for other sleep apneas}

Extensive epidemiological study has demonstrated that the vast majority of patients with sleep apnea syndrome have the obstructive type. In the 2006/2007 CIHI-DAD, a significant proportion of hospitalized sleep apnea patients were coded for 'other sleep apnea' (Figure 2). The most common health interventions administered to adult patients whose discharge diagnosis included 'other sleep apnea' were noninvasive CPAP/ BiPAP therapy (via a mask or cannula) (8.6\%) (CCI code 1.GZ.31.CB-ND), followed by polysomnography (6.1\%) (CCI code 2.AN.59.ZZ), CPAP/BiPAP therapy (via an endotracheal or tracheostomy tube) (5.1\%) (CCI code 1.GZ.31.CA-ND) and UPPP (3.6\%) (CCI code 1.FQ.78LA).

\section{DISCUSSION}

Hospital discharge abstract databases are increasingly being used to inform practice and research. The results of the present study showed that while hospitalized OSA patients in Canada shared similar demographic and clinical characteristics as those described in prospective epidemiological studies $(3,17,18)$, the prevalence of this condition was significantly less than the estimates of OSA in the general public $(2,3)$.

In our study, approximately $57.4 \%$ of the extracted records were for patients coded for OSA, but a significant portion of records $(42.6 \%)$ were coded for a diagnosis of 'other sleep apneas' (ICD-10-CA G.47.38). Given that prospective studies $(1,19)$ have demonstrated the majority of sleep apnea cases to be of the obstructive type, it is likely that many of the cases coded as 'other sleep apneas' are, in fact, miscoded OSAs. To gain a better understanding of this population of 'other sleep apnea' patients, we investigated their most common health interventions and determined that $\mathrm{CPAP} / \mathrm{BiPAP}$ therapy $(8.6 \%)$ and UPPP (3.6\%) were the most common treatments. This supports our hypothesis that this large population of 'other sleep apnea' patients likely have OSA. However, we were unable to determine from the CIHI-DAD whether this anomaly reflected issues related to clinical practice (diagnosis and documentation) or coding practices.

Since 2003, under the direction of CIHI, all provinces and territories have used ICD-10-CA codes, which should enable
TABLE 4

Disposition at discharge for adult patients coded with a discharge diagnosis that included obstructive sleep apnea, and according to the receipt of CPAP/BiPAP therapy: CIHI-DAD, fiscal year 2006/2007

\begin{tabular}{|c|c|c|c|}
\hline \multirow[b]{3}{*}{ Disposition category } & \multicolumn{3}{|c|}{ No CPAPI } \\
\hline & CPAP/BIPAP & BiPAP & \\
\hline & n (\%) & n (\%) & Total \\
\hline 1. Transferred to acute care & $16(4.9)$ & $338(5.2)$ & 354 \\
\hline 2. Transferred to continuing care & $32(9.8)$ & $305(4.7)$ & 337 \\
\hline 3. Transferred to other & $2(0.6)$ & $39(0.6)$ & 41 \\
\hline $\begin{array}{l}\text { 4. Discharged to home } \\
\text { with support services }\end{array}$ & $58(17.7)$ & $838(12.9)$ & 896 \\
\hline 5. Discharged home & $198(60.5)$ & $4740(73.1)$ & 4938 \\
\hline 6. Sign out & $5(1.5)$ & $47(0.7)$ & 52 \\
\hline 7. Died & $16(4.9)$ & $179(2.8)$ & 195 \\
\hline Total & $327(100)$ & $6486(100)$ & 6813 \\
\hline
\end{tabular}

Those receiving continuous positive airway pressure (CPAP)/bilevel positive airway pressure (BiPAP) therapy had a significantly different discharge disposition distribution, $P<0.0001$. Notably, they were much less likely to fall into the most common category 5, and more likely to fall into categories 2 and 4. CIHI-DAD Canadian Institute for Health Information Discharge Abstract Database

the clear identification of OSA in hospitalized patients. As evidenced by the low reported prevalence of OSA, it appears that this has not been achieved. A few possible explanations can be proposed for this finding. First, sleep apnea diagnosis is not being recorded in the patient charts to begin with. This may reflect a lack of appreciation by health care providers of OSA's designation as a type 1 or type 2 comorbid diagnosis. Second, even when sleep apnea syndrome is identified, the specific type may not be recorded in the patient's chart. Administrative coding is dependent on physicians and other health care professionals using the correct terminology when documenting diagnoses and interventions. For example, documenting the OSA patient's diagnosis as 'apnea' (ICD-10-CA code R.06) or 'sleep apnea' (ICD-10-CA code G.47.38) instead of 'obstructive sleep apnea' (ICD-10-CA code G.47.30) will result in classification error. Third, coders may also be unaware of OSA's designation as a type 1 or type 2 comorbid diagnosis and, therefore, are not abstracting it consistently.

Compliance with CPAP therapy is especially important in OSA patients with concomitant acute and chronic diseases and illness (11), and in those undergoing procedures associated with sedation, analgesia and anesthesia $(6,10,12,13)$. Despite current evidence-based recommendations, our study showed that a mere $4.8 \%$ of the hospitalized adult patients coded for OSA were abstracted with a CCI code for CPAP/BiPAP therapy during their stay. Currently, codes used in the CCI classification system do not permit the separation of noninvasive positive pressure therapies and, therefore, it is not possible to determine whether OSA patients received CPAP or BiPAP therapy. Therefore, the CIHI-DAD may overestimate the number of OSA patients receiving CPAP therapy because some OSA patients may have received BiPAP therapy for concomitant disorders other than OSA (eg, respiratory failure related to COPD). This study also revealed that $9.6 \%$ of OSA patients received the surgical intervention - UPPP. Interestingly, a recent Cochrane review (20) concluded that UPPP does not 
reduce daytime sleepiness, apnea or improve quality of life. Furthermore, it is associated with a high risk of long-term side effects, especially difficulty swallowing (21).

Our data revealed an interesting paradox - in the adult OSA group, the median length of stay was eight days for patients receiving CPAP/BiPAP therapy and was four days for those who did not receive $\mathrm{CPAP} / \mathrm{BiPAP}$ therapy. It is possible that this paradox reflects the fact that sicker patients are more likely to receive $\mathrm{CPAP} / \mathrm{BiPAP}$ therapy than healthier ones while in hospital. Furthermore, with respect to the disposition at discharge, patients receiving CPAP/BiPAP therapy had a significantly different discharge disposition distribution than those not receiving CPAP/BiPAP therapy. Specifically, CPAP/ BiPAP-treated patients were less likely to be discharged home and more likely to be transferred to continuing care or discharged home with support services - further descriptive of the health state of patients provided with CPAP/BiPAP therapy. Future studies that include data linkage and/or disease severity indexes may provide greater insight into the clinical management of OSA in seriously ill patients.

\section{Limitations of discharge abstract data}

There are several inherent weaknesses in the present study. First, the validity of our results depend on the completeness, specificity and accuracy with which data were collected in the CIHI-DAD. In this regard, the following concerns must be considered: inconsistencies in the reporting of hospital discharge data by institutions to the CIHI-DAD has, in the past, weakened the integrity of the national database. Fortunately, in the 2006/2007 fiscal year, there were a total of 864 valid institution numbers in the DAD frame, with only one small facility failing to submit separation data during this time period; the most common data quality problem cited by researchers is inaccuracies in coding for diagnoses and procedures. One of the conclusions of our study is that, based on general population prevalence rates for OSA, this condition in hospitalized patients is being seriously under reported. In a recent study aimed at validating the accuracy of the CIHIDAD (22), investigators compared the hospital discharge data against chart review. The results revealed a discrepancy rate of $23 \%$ for comorbid diagnostic codes and $7 \%$ for surgical procedure codes; a significant weakness in the data contained in the CIHI-DAD stems from a lack of specificity in the CCI codes of certain health interventions. In our study, for example, we would have favoured determining the percentage of OSA patients receiving its gold standard therapy - noninvasive CPAP. Unfortunately, the CCI classification system code for noninvasive CPAP therapy is 1.GZ.31.CB-ND, which is also the code for noninvasive BiPAP therapy, making these distinct procedures indistinguishable; for many of the health interventions specified in the CCI, there is no guarantee that, even if they are recorded in the patient's chart, they will be included in the patient's hospital discharge abstract. Coding in the CCI is based on a rubric of five characters (X.XX.XX) corresponding to three fields. The first field (X.XX.XX) is a number from 1 to 8 , which represents the type of intervention. For example, CCI codes that start with the number 1 are therapeutic, codes that start with the number 2 are diagnostic interventions and codes that start with the number 3 are diagnostic imaging interventions. The second field (X.XX.XX) contains two letters that represent the body system and the specific anatomical site, while the third field (X.XX.XX) represents the specific intervention. Currently, the only health interventions hospital-based coders are required to include in hospital discharge abstracts are those whose third field contains the number 50 or above (eg, X.XX.50). Health intervention codes with a third field below 50 fall into an optional coding category and, unless made mandatory by a specific department of health or institution, there is no guarantee of it being included. The CCI code for noninvasive CPAP/BiPAP therapy is 1.GZ.31.CB-ND, a fact that may account, at least in part, for the low reported use of $\mathrm{CPAP} / \mathrm{BiPAP}$ therapy seen in hospitalized patients with OSA. Second, not all populations of Canadian patients were represented in our data set. In the 2006/2007 CIHI-DAD, institutions in the province of Quebec were not part of the DAD frame and, therefore, it cannot be considered a true national database. Finally, a third limitation of hospital discharge data is that certain data elements such as laboratory values, test results, severity of illness, functional status or behavioural risk factors are often not present. Datasets lacking these details may prove to be inadequate for determining risk assessment, patterns of care, product or outcome of care.

Based on the epidemiological findings for the general population, we anticipated a higher prevalence of OSA and a greater reported use of CPAP therapy in hospitalized patients. In the process of investigating possible reasons for these anomalies, we discovered a number of issues related to the accuracy, specificity and completeness of the discharge data specific to OSA and its management. Hospital discharge data are the only feasible means through which a national perspective on the prevalence and management of chronic diseases such as OSA can be determined. Despite the CIHI-DAD's annual operating budget of $\$ 100$ million per year (23), the information housed in this particular database does not enable us to draw such conclusions. Before the CIHI-DAD can become a useful tool for determining clinical practice and resource allocation for OSA in Canada, advocacy is required.

ACKNOWLEDGEMENTS: The authors thank the Canadian Institute for Health Information (CIHI) for providing data for this study through the CIHI Graduate Student Data Access Program to Kathy F Spurr. Additional funding for this work was provided by a Research Development Grant to Robert W Gilbert, provided by the Faculty of Health Professions, Dalhousie University (Halifax, Nova Scotia). The authors also thank Cheryl MacDonald and Lisa Dillman for their assistance in preparing the manuscript.

\section{REFERENCES}

1. Roehrs T, Conway W, Wittig R, Zorick F, Sicklesteel J, Roth T. Sleep-wake complaints in patients with sleep-related respiratory disturbances. Am Rev Respir Dis 1985;132:520-3.

2. Punjabi NM. The epidemiology of adult obstructive sleep apnea. Proc Am Thorac Soc 2008;5:136-43.

3. Young T, Palta M, Dempsey J, Skatrud J, Weber S, Badr S. The occurrence of sleep-disordered breathing among middle-aged adults. N Eng J Med 1993;328:1230-5.

4. Kapur V, Strohl KP, Redline S, Iber C, O'Conner G, Nieto J. Under-diagnosis of sleep apnea syndrome in US communities. Sleep Breath 2002;6:49-54.

5. Young T, Evans L, Finn L, Palta M. Estimation of the clinically diagnosed proportion of sleep apnea syndrome in middle aged men and women. Sleep 1997;20:705-6. 
6. Fleetham J, Ayas N, Bradley D, et al. Canadian Thoracic Society guidelines: Diagnosis and treatment of sleep disordered breathing in adults. Can Respir J 2006;13:387-92.

7. Giles TL, Lasserson TJ, Smith BJ, White J, Wright J, Cates CJ. Continuous positive airways pressure for obstructive sleep apnoea in adults. Cochrane Database Syst Rev 2006;(3):CD001106.

8. McDaid C, Griffin S, Weatherly H, et al. Continuous positive airway pressure devices for the treatment of obstructive sleep apnoea-hypoponea syndrome: A systematic review and economic analysis. Health Technol Assess 2009;13:1-162.

9. Adult Obstructive Sleep Apnea Task Force of the American Academy of Sleep Medicine. Clinical guideline for the evaluation, management and long-term care of obstructive sleep apnea in adults. J Clin Sleep Med 2009;5:263-76.

10. Liao P, Balaji Y, Vairavanathan S, Zilberman P, Chung F. Postoperative complications in patients with obstructive sleep apnea: A retospective matched cohort study. Can J Anesth 2009;56:819-28.

11. Anselm AH, Gauthier N, Beanlands RS, Haddad H. Sleep apnea in chronic heart failure. Curr Opin Cardiol 2008;23:121-6.

12. Meoli AL, Rosen CL, Kristo D, et al. Upper airway management of the adult patient with obstructive sleep apnea in the perioperative period-avoiding complications. Sleep 2003;26:1060-5.

13. Gross JB, Bachenberg KL, Benumof JL, et al; American Society of Anesthesiologists Task Force on Perioperative Management of Patients with Obstructive Sleep Apnea Practice guidelines for the perioperative management of patients with obstructive sleep apnea: A report by the American Society of Anesthesiologists Task Force on Perioperative Management of patients with obstructive sleep apnea. Anesthesiology 2006;104:1081-93.

14. Smith I, Haniffa M, Lasserson TJ. Interventions to improve use of continuous positive airway pressure for obstructive sleep apnoea. Cochrane Database Syst Rev 2004;(4):CD003531.
15. Wolkove N, Baltzan M, Kamel H, Dabrusin R, Palayew M. Long-term compliance with continuous positive airway pressure in patients with obstructive sleep apnea. Can Respir J 2008;15:365-9.

16. Canadian Institute for Health Information. Coding variations in the discharge abstract database (DAD) data (2003). <http://secure. cihi.ca/cihiweb/dispPage.jsp?cw_page=download_form_e\&cw $\mathrm{sku}=C V D A D P D F \& \mathrm{cw} \_\mathrm{ctt}=2 \& \mathrm{cw} \_$dform $=$null $>$ (Accessed on March 1, 2009).

17. Somers VK, White DP, Amin R, et al. Sleep apnea and cardiovascular disease: An American Heart Association/American College of Cardiology Foundation Scientific Statement from the American Heart Association Council for High Blood Pressure Research Professional Education Committee, Council on Clinical Cardiology, Stroke Council, and Council on Cardiovascular Nursing. J Am Coll Cardiol 2008;52:686-717.

18. Canadian Institute for Health Information. Inpatient/Acute Admissions by Province of Facility Location. <http://secure.cihi.ca/ cihiweb/dispPage.jsp?cw_page=home_e> (Accessed on March 1, 2009).

19. Eckert DJ, Jordan AS, Merchia P, Malhotra A. Central sleep apnea: Pathophysiology and treatment. Chest 2007;131:595-607.

20. Sundaram S, Lim J, Lasserson TJ. Surgery for obstructive sleep apnoea in adults. Cochrane Database Syst Rev 200519;(4):CD001004.

21. Franklin KA, Anttila H, Axelsson S, et al. Effects and side-effects of surgery for snoring and obstructive sleep apnea - a systematic review. Sleep 2009;32:27-36.

22. Canadian Institute for Health Information Discharge abstract database data quality re-abstraction study. Ottawa: Canadian Institute for Health Information, 2002:1-70.

23. Connecting Canada's Health Data - Canadian Institute for Health Information Annual Report, 2009-2010 (April 2010). $<$ http://www.cihiannualreport.ca/en/financial-overview/ management-discussion-analysis $>$ (Accessed on September 13, 2010). 


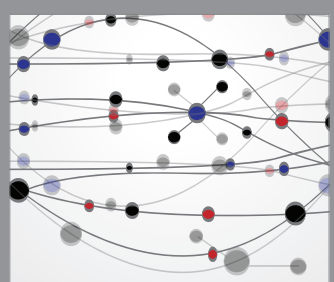

The Scientific World Journal
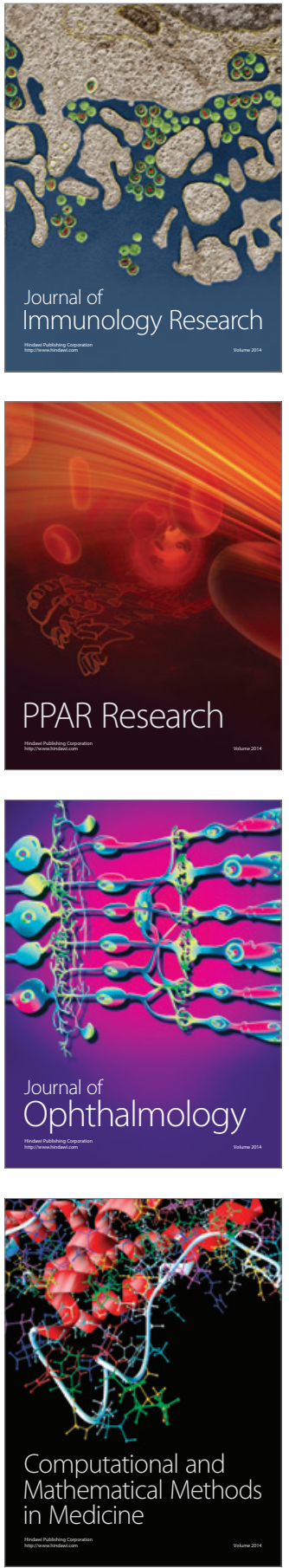

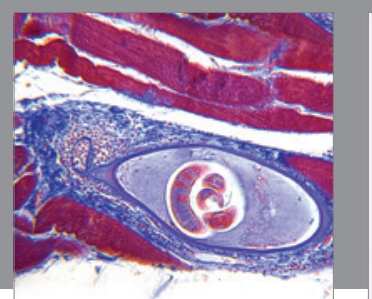

Gastroenterology Research and Practice

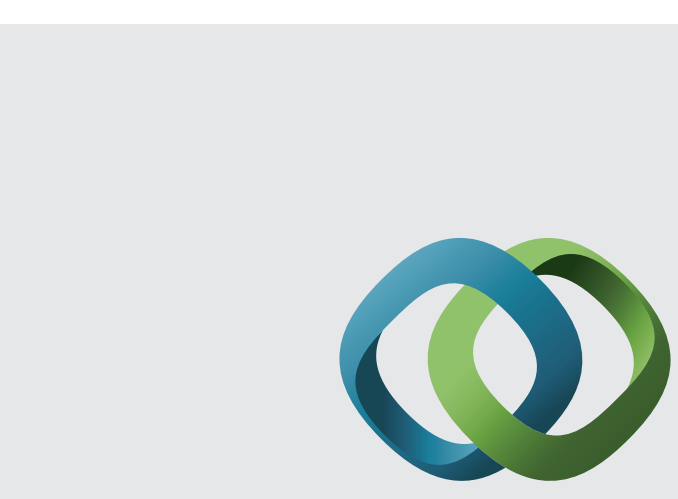

\section{Hindawi}

Submit your manuscripts at

http://www.hindawi.com
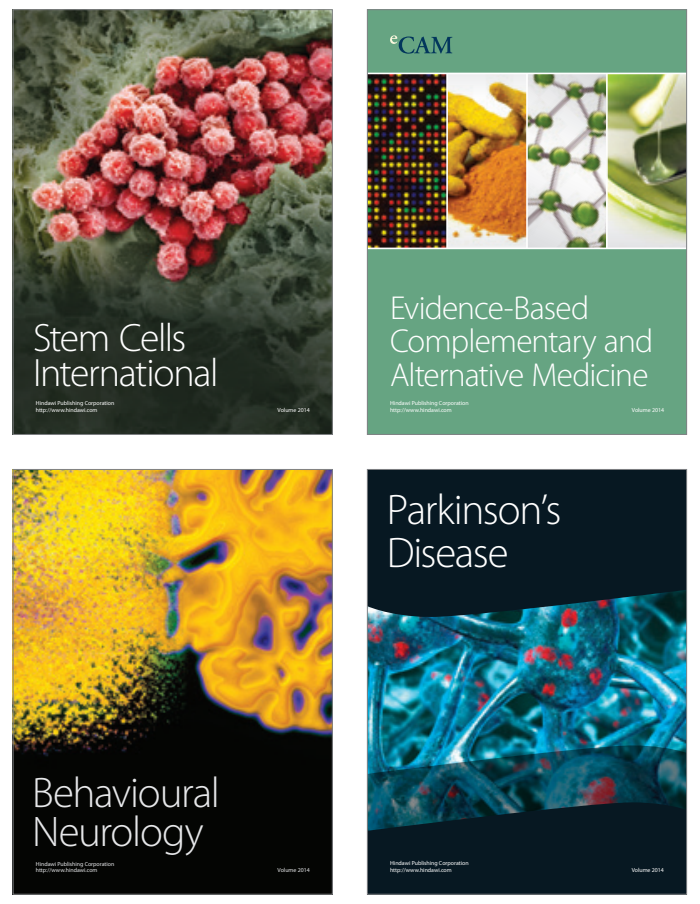
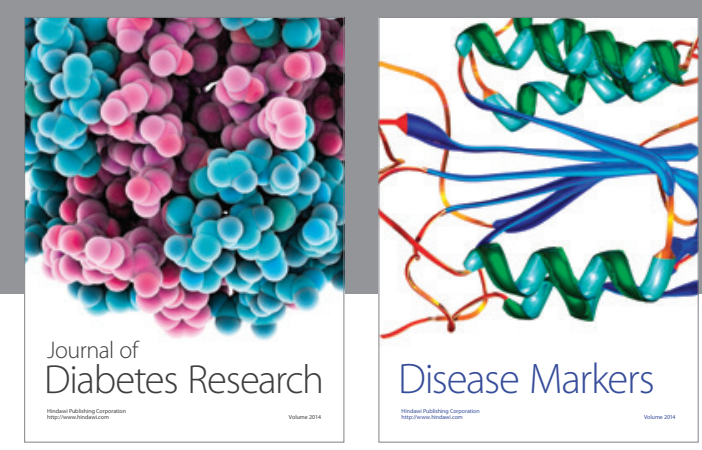

Disease Markers
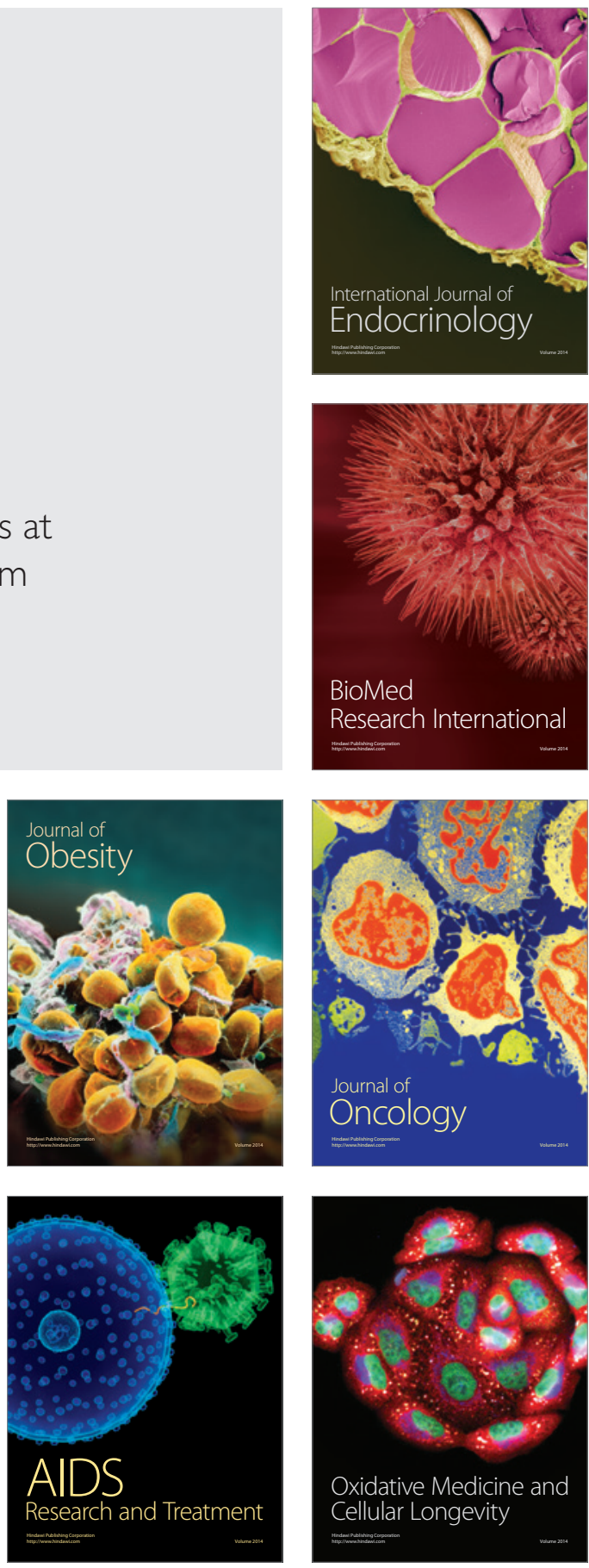